\title{
Giyilebilir Teknolojik Ürünlerin Tasarımında Etkili Olan Faktörlerin Best-Worst Metodu (BWM) İle Değerlendirilmesi*
}

\section{Evaluation of Factors Effective in the Design of Wearable Technological Products Using the Best-Worst Method (BWM)}

\author{
Gözde Koca $^{*}$, Ezgi Dilan Urmak Akçakaya²
}

Geliş / Received: 27/12/2020

Revize / Revised: 11/02/2021

Kabul / Accepted: 15/02/2021

ÖZ

Teknolojinin gelişimi ile birlikte sadece bilgisayarlar ve akıllı telefonlar değil, kullandığımız kıyafet ve aksesuarlar da akıllı cihaza dönüşebilmektedir. Kullanıcı veri alışverişi daha küçük cihazlarla, kullanıcının vücuduna monte durumunda gerçekleşmesi birçok açıdan kolaylık sağlamaktadır. Bu nedenle giyilebilir teknlojik ürünlerin tasarımında dikkat edilmesi gereken faktörler önem arz etmektedir. Bu çalışmada da, giyilebilir teknolojik ürünlerin tasarımında etkili olan faktörlerin, öznel kriter ağırlıklandırma yöntemlerinden biri olan Best-Worst metodu ile değerlendirilmesi amaçlanmıştır. Bu nedenle giyilebilir teknolojik ürünlerin tasarımında uzman beş kişilik bir ekip tarafından değerlendirmeler yapılmıştır. Değerlendirmelerin çözümlemeleri için BWM-Solver tercih edilmiştir. Sonuçta, en önemli ana faktörün "Ak1llılık", en az önemli ana faktörün ise "Moda" olduğu, en önemli alt faktörün "Bilgi Sağlama”, en az önemli alt faktörün ise “Teknoloji” olduğu belirlenmiştir. Ayrıca BWM yönteminin tutarlılığını ve kullanışlılığını göstermek için bir duyarlılık analizi yapılmıştır.

Anahtar Kelimeler- Giyilebilir Teknolojik Ürün, Çok Kriterli Karar Verme, Best-Worst Metot

\begin{abstract}
With the development of technology, not only computers and smart phones, but also the clothes and accessories we use can turn into smart devices. User data exchange with smaller devices provides convenience in many aspects when mounted on the user's body. Therefore, it is important to pay attention to the design of wearable technological products. In this study, it is aimed to evaluate the factors that are effective in the design of wearable technological products with Best-Worst method, which is one of the subjective criteria weighting methods. For this reason, evaluations were made by a team of five experts in the design of wearable technological products. BWM-Solver was preferred for analysis of the evaluations. As a result, it was determined that the most important main factor was "Intelligence", the least important main factor was "Fashion", the most important sub factor was "Information Providing," and the least important sub factor was "Technology". Also, a sensitivity analysis was conducted to show the consistency and usefulness of the BWM method.
\end{abstract}

Keywords- Wearable IT Product, Multi Criteria Decision Making, Best-Worst Method

\footnotetext{
*Bilecik Şeyh Edebali Üniversitesi Etik Kurulu'nun 26.02.2021 tarihli ve 3 sayılı toplantısının 1 nolu kararı ile etiğe aykırılık bulunmadığına karar verilmiștir.

1*Sorumlu yazar iletişim: gozde.koca@bilecik.edu.tr (https://orcid.org/0000-0001-6847-6812)

Ișletme Bölümü, Bilecik Şeyh Edebali Üniversitesi, Iktisadi ve İdari Bilimler Fakültesi, Bilecik, Türkiye

2İletișim: ezgidilanurmak@ardahan.edu.tr (https://orcid.org/0000-0003-3472-1837)
}

Iş̧letme Bölümü, Ardahan Üniversitesi, İktisadi ve İdari Bilimler Fakültesi, Ardahan, Türkiye 


\section{GíRiş}

Son zamanlarda teknolojinin gelişmesi ile birlikte yeni kullanım alanlarına yönelik birçok yenilikçi ve yaratıcı ürünler geliştirilmektedir. Bu ürünler arasında giyilebilir teknoloji ürünleri de yer almaktadır[1]. Giyilebilir teknoloji, akıllı ve yardımcı sistemlerin kullanıcının günlük faaliyetlerini kesintiye uğratmayacak ve kullanıcıyı rahatsız etmeyecek şekilde aksesuar ya da kıyafetlere entegre edilmesi ile ortaya çıkan bilgisayar teknolojileridir [2]. İlk giyilebilir teknoloji ürünü 1961 yllında geliştirilmiştir [3]. Teknolojinin daha da ilerlemesi ile 1980'li yıllarda giyilebilir teknoloji alanındaki gelişmeler hız kazanmıştır. 2000'li yıllara gelindiğinde ise sağllk, savunma ve eğlence sektörlerindeki gelișmeler neticesinde bu ürünlere yönelik gelișmeler daha da hızlanmışıtır [4]. Günümüzde ise giyilebilir teknolojik ürünler tekstil ve moda tasarımı alanlarına dahi yön vermeye başlamıştır [5].

Giyilebilir teknolojik ürünler, kullanıcıların ya da nesnelerin hareketlerini, pozisyonlarını ve ağırlıklarını algılama; kullanıcıların ruh halini, zihinsel ve fiziksel durumunu ölçme; sesleri algılama, konuşmayı yorumlama; bilgisayar görüntüsü tespit etme; kullanıcıların bulunduğu ortamın koşullarını izleme gibi özelliklere sahiptir. Giyilebilir teknolojiler bu mekanik (konum, yer değiştirme, hız, enerji), biyolojik (kalp atış hızı, vücut sıcaklığı, sinirsel aktivite, solunum hızı), akustik (ses, ses perdesi, frekans), optik (kırılma, 1şık dalgası frekansı, parlaklık) ve çevresel bilgileri (sıcaklık, nem) ölçmek için ise çok çeşitli sensörler içermektedirler [6]. Kullanıcılar bu sensörler sayesinde kişisel ölçümler gerçekleştirerek günlük yaşamlarının hemen hemen her yönünü izleyebilmektedirler [7]. Akıllı sensörlere sahip olan bu ürünler veri aktarımını internet aracıllı̆ı ile sağlamaktadırlar [8]. En yaygın kullanılan giyilebilir teknolojik ürünlere örnek olarak sporcu bileklikleri, akıllı saatler ve akıllı bileklikler verilebilir [9].

Giyilebilir teknolojik ürünler sayesinde kullanıcının hayatı kolaylaşmakta ve böylelikle hayat kalitesi de artmaktadır. Sağlık, spor, eğitim ve üretim gibi alanlarda kullanılan ve hayatı kolaylaştıran bu ürünler, tüketici istek ve ihtiyaçlarına göre geliştirilmekte böylece her geçen gün daha farklı ürünler ortaya çıkmaktadır. Ancak geliştirilen bu ürünlerin kullanımında istenmeyen durumlarla karşı karşıya kalınabilmekte ürünler işlevselliğini yitirebilmektedir [10]. Bu olumsuz sonuçların önlenmesi için ürünler geliştirilirken tasarım aşamasına gereken önem verilmelidir. Ayrıca tüketici istek ve ihtiyaçlarının ön planda tutulması ile geliştirilen giyilebilir teknolojik ürünlerin tasarımında dikkate alınması gereken birçok faktörden söz edilebilir. Ancak karar vericinin tasarım açısından önceliği hangi faktöre vermesi gerektiğine karar verebilmesi oldukça güçtür. Bu kapsamda, çok kriterli karar verme yöntemleri, karar vericinin birçok faktörü aynı anda değerlendirebilmesine imkân tanıması açısından işlevsel yöntemlerdir.

İnsanlar, yaşamın her anında karar verme problemleri ile karșı karșıya kalmaktadır. Bu problemlerin çözümünde birden fazla kriterin dikkate alınması gerekliliği, karar verme sürecini oldukça karmaşık hale getirmektedir. Örneğin, otomobil almak isteyen bir kişi motor gücü, yakıt tüketimi, konfor, iç hacim, güvenlik gibi birçok kriter açısından tüm alternatifleri değerlendirerek kendisi için en uygun olan otomobili belirlemek durumundadır. Bunun gibi ya da bundan çok daha karmaşık olan çok kriterli karar verme problemlerinin çözümünde kullanılmak üzere bilim insanları tarafından çok kriterli karar verme yöntemleri geliştirmiştir.

Çok kriterli karar verme yöntemleri, alternatifleri, farklı ölçü birimlerine sahip olan birden fazla kriter açısından değerlendirerek en iyi alternatifin seçilmesini sağlayan araçlardır. Karar vericinin amacı seçme, sıralama ve sinıflandırma problemlerinin her birinde farklı olabilmektedir. Seçme probleminde karar verici en iyi alternatifi belirlemeyi amaçlarken; sıralama probleminde alternatifleri iyiden kötüye doğru sıralamayı amaçlamaktadır. Sınıflandırma probleminde ise alternatifler amaca göre sinıflandırılmaktadır[11].

Çok kriterli karar verme yöntemlerinin bir diğer işlevi ise kriter ağırlıklarının hesaplanabilmesine ve böylece kriterlerin önem derecelerinin belirlenebilmesine imkan tanımasıdır. Kriter ağırlıklarının hesaplanmasında birçok subjektif ve objektif yöntemlerin kullanıldığı görülmektedir[12]. Bu yöntemlere örnek olarak Entropi, BestWorst, CRITIC (Criteria Importance Through Intercritera Correlation) yöntemleri verilebilir.

Bu çalışmada giyilebilir teknolojik ürünlerin tasarımında etkili olan 3 ana faktörün ve bu faktörlere ait alt faktörlerin önceliklendirilmesi amaçlanmıştır. Bu bağlamdagiyilebilir teknolojik ürünlerin tasarımında etkili olan faktörler akıllılık, mobilite ve moda olarak belirlenmiştir. Akıllılık ana faktörü; bilgi sağlama, sezgisel iletişim, iletişim ağı ve otomasyon olmak üzere 4 alt faktörden oluşmaktadır. Mobilite ana faktörü; yaygın bilişsim, kolaylık, yerini belirleme ve kişiselleştirme olmak üzere 4 alt faktörden meydana gelmektedir. Moda ana faktörü ise; sembol, kültür, yenilik, estetik ve teknoloji olmak üzere 5 alt faktörden oluşmaktadır. Faktörlerin 
önceliklendirilmesi sübjektif yöntem olan Best-Worst Metodu (BWM) ile gerçekleştirilmiştir. BWM metodunun seçilmesinin nedeni, ele alınan faktörleri birbirleriyle değil de, en iyi ve en kötü faktöre göre değerlendirmesi veböylelikle tüm faktörlerin ikili karşılaştırmalarının yapıldığı diğer sübjektif yöntemlerin aksine BWM metodunda daha az sayıda ikili karşılaştırmanın yapılmasıdır. Bu durum hesaplama zamanının azalmasını sağlamaktadır. Aynı zamanda verilen yanıtların tutarlılıklarını ölçmesi de bir diğer tercih sebebidir.Söz konusu faktörler ise giyilebilir teknolojik ürünlerin tasarımında uzman 5 karar vericinin görüşleri alınarak değerlendirilmiştir.

$\mathrm{Bu}$ çalışma konunun genel çerçevesinin değerlendirildiği giriş bölümü ile birlikte yedi bölümden oluşmaktadır. BWM ve giyilebilir teknolojik ürünler ile ilgili literatür taraması, BWM metodu, uygulama, duyarlılık analizi bölümüne ek, son olarak sonuç bölümü yer almaktadır.

\section{LITERATÜR TARAMASI}

BWM ve giyilebilir teknolojik ürünler ile ilgili çalışmalara Tablo 1'de yer verilmektedir.

Tablo 1. Literatür İncelemesi

\begin{tabular}{|c|c|}
\hline \multicolumn{2}{|l|}{ Best-Worst Metodu ile Yapılan Çalışmalar } \\
\hline BWM yönteminin önerilmesi & [13] \\
\hline Lojistik sektöründe hizmet kalitesinin ölçülmesi & [14] \\
\hline Hayat-dışı sigorta şirketlerinin performans değerlendirmesi & [15] \\
\hline Sürdürülebilir çoklu taşıma rotası tespiti için gerekli sürdürülebilirlik göstergelerinin önem düzeyinin belirlenmesi & [16] \\
\hline $\begin{array}{l}\text { Bir konaklama işletmesinin dış kaynak seçiminde göz önünde bulundurduğu kriterlerin önem derecelerinin } \\
\text { belirlenmesi }\end{array}$ & [17] \\
\hline Kurumsal kaynak planlama sistemi seçiminde dikkat edilmesi gereken kriterlerin değerlendirilmesi & [18] \\
\hline Yol güvenliği ile ilgili sürücü davranış faktörlerinin değerlendirilmesi & [19] \\
\hline Bulanık BWM yönteminin geliştirilmesi & [20] \\
\hline İran sahil bölgesindeki yatırım firsatlarının değerlendirilmesi & [21] \\
\hline Geleneksel ve çevresel kriterleri entegre eden tedarikçi seçimi & [22] \\
\hline Petrolle kirlenmiş toprakların arıtılması için en iyi stabilizasyon / katılaştırma yönteminin seçilmesi & [23] \\
\hline $\begin{array}{l}\text { Kentsel kanalizasyon çamurunun arıtılmasına yönelik teknolojilerin sürdürülebilirlik değerlendirmesinde kriterlerin } \\
\text { ağırlıklandırılması }\end{array}$ & [24] \\
\hline Tedarik zincirlerinin sosyal sürdürülebilirliğinin değerlendirilmesi & [25] \\
\hline Tedarikçi seçimi, Su kıtllı̆ı yönetimi, İnovasyon yönetimi, Bilimsel eserlerin kalite değerlendirmesi & $\begin{array}{l}{[26],[27],[28],} \\
{[29]}\end{array}$ \\
\hline Bulanık Best Worst yöntemi ve uygulama örneklerinin değerlendirilmesi & [30] \\
\hline Best Worst yöntemi ile ilgili yapılan çalışmaların bibliyometrik analizi & [31] \\
\hline Lojistik performans endeks göstergelerinin göreceli önem değerlerinin ölçülmesi & [32] \\
\hline $\begin{array}{l}\text { BWM'den elde edilen optimum aralıkların konsantrasyonunu kontrol etmek için geliştirilen konsantrasyon oranının } \\
\text { tanıtılması }\end{array}$ & [33] \\
\hline Üniversite-sanayi doktora projelerinin etkinliğinin ölçülmesi & [34] \\
\hline İdeal özel okul seçimini etkileyen kriterlerin BWM ve FUCOM yöntemleri ile derecelerinin belirlenmesi & [35] \\
\hline Finansal oranların önem düzeylerinin hesaplanması & [36] \\
\hline Ülkelerin seyahat ve turizm rekabetedebilirliğinin değerlendirilmesi & [37] \\
\hline En iyi radyo frekanslı tanımlama sisteminin belirlenmesi & [38] \\
\hline \multicolumn{2}{|l|}{ Giyilebilir Teknoloji ve Ürünler ile İlgili Yapılan Çalışmalar } \\
\hline İletken iplik alımında etkili kriterler arasındaki ilişkilerin DEMATEL yöntemi ile belirlenmesi & [39] \\
\hline Giyilebilir Sağlık Teknolojilerinin AHP, PROMETHEE ve TOPSIS yöntemleri ile değerlendirilmesi & [40] \\
\hline $\begin{array}{l}\text { CRITIC ve MAUT yöntemleri ile farklı akıllı saat markalarından kullanıcıya en çok faydayı sağlayan markanın tespit } \\
\text { edilmesi }\end{array}$ & [41] \\
\hline Bulanık DEMATEL ve EDAS yöntemleri kullanılarak sporcular için akıllı bileklik seçimi & [42] \\
\hline $\begin{array}{l}\text { Tüketicilerin giyilebilir teknolojileri benimsemesine yönelik davranışsal niyetleri ve kullanımları üzerinde etkili } \\
\text { faktörlerin değerlendirilmesi }\end{array}$ & [43] \\
\hline Bireysel ölçüm ve giyilebilir teknolojinin sağlık hizmetleriyle bütünleştirilmesinin değerlendirilmesi & [44] \\
\hline Tüketicilerin giyilebilir teknolojileri kabulünü etkileyen faktörlerin belirlenmesi & [45] \\
\hline $\begin{array}{l}\text { Tüketicilerin giyilebilir teknolojik ürünleri satın alma karar sürecinde algıladıkları risk faktörleri ve sebeplerinin tespit } \\
\text { edilmesi }\end{array}$ & [46] \\
\hline
\end{tabular}


Tablo 1'den de anlaşılacağı gibi giyilebilir teknolojik ürünlere ait bazı ürünler ÇKKV problemleri ile değerlendirilmiştir. Bu çalışmaların genellikle giyilebilir teknolojik ürünlerin seçimine yönelik çalışmalar olduğu; ancak Türkiye'de giyilebilir teknolojik ürünlerin özellikle tüketiciler tarafından talep edilip, dikkate alınan tasarım faktörleri üzerinden incelendiğinde Türkiye'de böyle bir çalışmaya rastlanılmadığ 1 görülmektedir. Bu çalışmanın literatüre olan katkısı ise giyilebilir teknolojik ürünlerin tasarımında etkili olan faktörlerin ÇKKV yöntemi ile önceliklendirilmesidir. Söz konusu bu faktörler uzman görüşü ve literatür değerlendirilmesi yapılarak belirlenmiştir.Faktör önceliklerinin belirlenmesinde sübjektif yöntemlerden biri olan BWM yöntemi kullanılmıştır. Faktörlere ait nicel verilerin olmaması, BMW yönteminde değerlendirmelerin tüm faktörlerin ikili karşılaştırmasına gerek duyulmadan daha az sayıda karşılaştırmaya olanak sağlaması böylelikle değerlendirme süresinin nispeten daha az olması nedeniyle BWM yöntemi tercih edilmiştir.

\section{BEST-WORST METOT (BWM)}

Karar vericiler, birçok ana faktörü ve alt faktörü değerlendirme sürecinde, çok kriterli karar verme yöntemlerinden birini kullanmaktadır. Bu yöntemlerden biri de Best-Worst metotdur [13], [19], [49], [50]. BWM, en iyi faktörü diğer kriterlerle ve diğer tüm faktörleri en kötüyle karşılaştıran bir kıyaslama karar verme yöntemidir. BWM ile karar vericilerin tüm faktörler arasında ikili karşılaştırmalara gerek yoktur. Sadece en iyi ve en kötü faktörün tanımlanması ve ardından en iyi / en kötü faktör ile diğer faktörler arasında ikili karşılaştırmalar yapmak gerekmektedir. Farklı faktörlerin ağırlıklarını belirlemek için maksimum matematiksel model oluşturulmuştur. Yöntemin güvenilirliğini kontrol etmek için yeni bir tutarlılık oranı tanımı yapılmıştır. Ancak BWM'de, faktör sayısı çok fazla olduğunda hangi faktörün en iyi veya en kötü olduğunu belirlemek kolay değildir. Bu nedenle, en iyi veya en kötü faktörleri belirlemek için özel bir prosedür uygulamak gerekir. BWM'nin en büyük katkısı, karar vericilerin önce en iyi ve en kötü faktörleri tanımlaması ve ardından bu iki faktörün her biri (en iyi ve en kötü) ve diğer faktörler arasında ikili karşılaştırmalar yapmalarıdır.

Yöntemin uygulama adımları aşağıdaki gibidir:

Adım 1: Bir dizi karar kriterinin belirlenmesi gerekiyor. Bu adımda, karar verici karar vermek için kullanılan n kriterini $\left\{C_{1}, C_{2}, \ldots \ldots, C_{n}\right\}$ belirler.

Adım 2: En iyi (en çok istenen, en önemli) ve en kötü (en az istenen, en az önemli) kriterler belirlenir.

Adım 3: 1 ile 9 arasında bir sayı kullanılarak en iyi kriterin belirlenmesi ve diğer tüm kriterlere göre tercih oranının belirlenmesi aşamasıdır. 1 ile 9 arasında bir sayı kullanılarak en iyi kriterin tercihinin belirlendiği aşamadır. Diğer tüm kriterler (1: eşit derecede önemli, 3: orta derecede daha önemli, 5: çok önemli, 7: çok daha önemli, 9: çok önemli). Bu adım sonucunda en iyiden diğerine hareket eden En İyi-Diğerleri (AB) adlı bir vektöre ulaşılır. Bu vektör aşağıdaki gibidir:

$A_{B}=\left(a_{B 1}, a_{B 2}, \ldots, a_{B n}\right)$,

$A_{B}$ vektöründeki her bir $a_{B j}, \mathrm{j}$ kriterine göre en iyi kriter B'nin tercihini gösterir.

Ayrıca $a_{B B}=1$. Bu, en önemli kriterin onunla karşılaştırıldı̆̆ı anlamına gelir.

Adım 4: 1 ile 9 arasında bir sayı kullanarak diğer tüm kriterlerin en kötü tercih edilen kritere göre tercih oranlarının belirlenmesi ile ilgilidir. Bu adımda diğer kriterlerin en kötü kritere göre göreli önemi karar verici tarafından belirlenmiştir. 1'den 9'a kadar bir sayı kullanarak, bu adımın bir sonucu olarak, vektörün en kötüsü aşağıdaki gibi olmalıdır:

$$
A_{w}=\left(a_{1 W}, a_{2 W}, a_{3 W}, \ldots, a_{n W}\right)^{T},
$$

Bu vektörde, her bir $a_{j W}$, en kötü kriter W'ye kıyasla j kriterinin tercihini belirtir. Ve ayrıca $a_{W W}=1$, bu, en kötü kriterin onunla karşılaştırıldığg anlamına gelir.

Adım 5: Son adımda her kriter için en uygun ağırlık belirlenmelidir. 


$$
\left(W_{1}^{*}, W_{2}^{*}, W_{3}^{*}, \ldots \ldots, W_{n}^{*}\right)
$$
belirlemektir.

$\mathrm{Bu}$ adımdaki amaç, maksimum mutlak farkları sağlamak için kriterlerin optimal ağırlıklarını

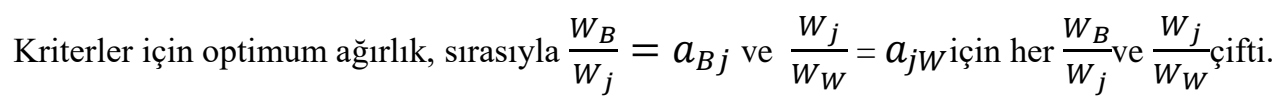

J değerleri bulunmalıdır $\left\{\left|w_{B}-a_{B j} w_{j}\right|,\left|w_{j}-a_{j w} w_{w}\right|\right\}$ burada maksimum mutlak farklar en aza indirilir. Bu nedenle, aşağıdaki min - maks modeline dönüştürülmüştür:

Kisitlamalar altında, $\operatorname{minmax}_{j}\left\{\left|w_{B}-a_{B j} w_{j}\right|,\left|w_{j}-a_{j w} w_{w}\right|\right\}$

$\sum_{j} w_{j}=1$

$\mathrm{w}_{\mathrm{j}} \geq 0$

Problem denklemi aşağıdaki doğrusal programlama problemine aktarılmıştır:

$$
\begin{aligned}
& \min \xi^{L} \\
& \left|\frac{W_{B}}{W_{j}}-a_{B j}\right| \leq \xi, \\
& \left|\frac{W_{j}}{W_{w}}-a_{j w}\right| \leq \xi, \\
& \sum_{j} w_{j}=1 \\
& \mathrm{w}_{\mathrm{j}} \geq 0,
\end{aligned}
$$

Adım 6: Yöntemin son aşamasında yapılan değerlendirmelerin tutarlılığı test edilir. Tablo 2' de gösterilen tutarlılık endeks değerlerinden yararlanılarak, tutarlılık oranı aşağıdaki gibi hesaplanmaktadır.

Tutarlılık Oranı $(\mathrm{TO})=\xi /$ Tutarlılık endeks değeri (TE)

Tutarlılık oranı sıfıra yaklaştıkça yapılan değerlendirmelerin daha tutarlı olduğu, 1'e doğru yaklaştıkça ise daha az tutarlı olduğunu ifade etmek doğru olacaktır.

Tablo 2. Tutarlılık Endeks Değerleri

\begin{tabular}{|l|l|l|l|l|l|l|l|l|l|}
\hline $\boldsymbol{a}_{B \mathrm{~W}}$ & 1 & 2 & 3 & 4 & 5 & 6 & 7 & 8 & 9 \\
\hline TE & 0,00 & 0,44 & 1,00 & 1,63 & 2,30 & 3,00 & 3,73 & 4,47 & 5,23 \\
\hline
\end{tabular}

\section{UYGULAMA}

Çalışma kapsamında, giyilebilir teknolojik ürünlerin tasarımında etkili olan faktörlerin BWM metodu ile önceliklendirilmesi amaçlanmıştır. Bu faktörler; akıllılık (F1), mobilite (F2) ve moda (F3) olmak üzere 3 ana faktörden oluşmaktadır. Akıllılık ana faktörü; bilgi sağlama (F11), sezgisel iletişim (F12), iletişim ağı (F13) ve otomasyon (F14) olmak üzere 4 alt faktörden oluşmaktadır. Mobilite ana faktörü; yaygın bilişim (F21), kolaylık (F22), yerini belirleme (F23) ve kişiselleştirme (F24) olmak üzere 4 alt faktörden meydana gelmektedir. Moda ana faktörü ise; sembol (F31), kültür (F32), yenilik (F33), estetik (F33) ve teknoloji (F34) olmak üzere 5 alt faktörden oluşmaktadır. Bu faktörler, Bilecik Şeyh Edebali Üniversitesi Etik Kurulu'nun 26.02.2021 tarihli ve 3 sayılı toplantısının 1 nolu kararıyla etik kurul izni alınarak, giyilebilir teknolojik ürünlerin tasarımında uzman 5 karar verici (KV) tarafindan değerlendirilmiştir. Bu karar vericilerin tümünün uzmanlığı en az 5 yll olup, alanlarında yönetici statüsünde olan uzmanlardır. Uzman değerlendirmeleri sonucu elde edilen görüşler https://bestworstmethod.com/software/ sitesinden indirilen BWM-Solver ile çözümlenmiştir. Söz konusu 5 karar verici tarafından değerlendirilmiş, olan ana faktörlerin değerlendirilmeleri Tablo 3’te verilmiştir. 
Tablo 3. Ana faktörlerin değerlendirilmeleri

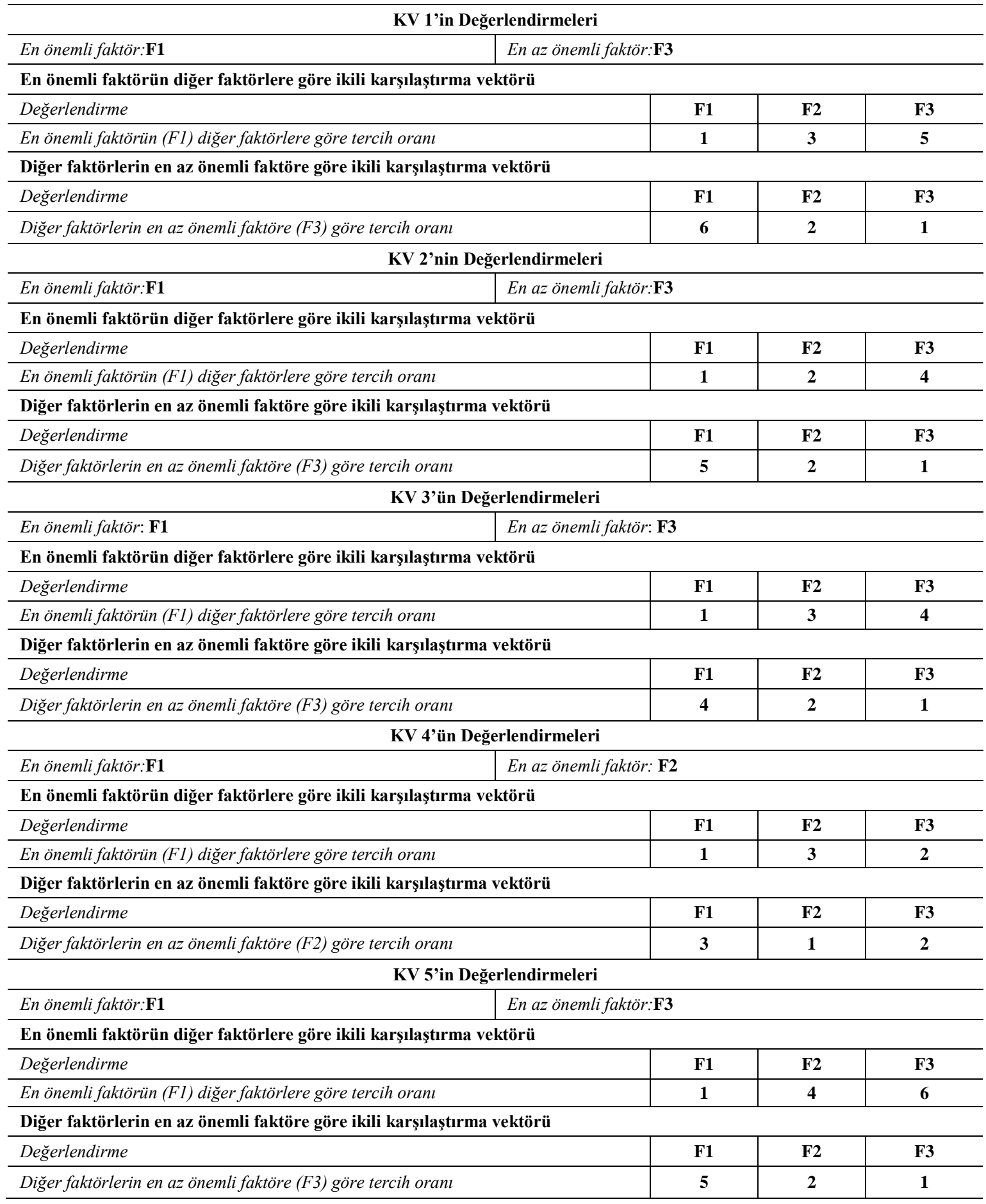


Akıllılık ana faktörüne ait alt faktörlerin değerlendirmeleri ise Tablo 4'te verilmiştir.

Tablo 4. Akı1ll11k ana faktörüne ait alt faktörlerin değerlendirmeleri

\begin{tabular}{|c|c|c|c|c|c|}
\hline \multicolumn{6}{|c|}{ KV 1'in Değerlendirmeleri } \\
\hline En önemli faktör:F11 & \multicolumn{5}{|c|}{ En az önemli faktör: $\mathbf{F 1 2}$} \\
\hline \multicolumn{6}{|c|}{ En önemli faktörün diğer faktörlere göre ikili karşılaştırma vektörü } \\
\hline \multicolumn{2}{|l|}{ Değerlendirme } & F11 & F12 & F13 & F14 \\
\hline \multicolumn{2}{|l|}{ En önemli faktörün (F11) diğer faktörlere göre tercih oranı } & 1 & 4 & 3 & 2 \\
\hline \multicolumn{6}{|c|}{ Diğer faktörlerin en az önemli faktöre göre ikili karşılaştırma vektörü } \\
\hline \multicolumn{2}{|l|}{ Değerlendirme } & F11 & F12 & F13 & F14 \\
\hline \multicolumn{2}{|l|}{ Diğer faktörlerin en az önemli faktöre (F12) göre tercih oranı } & 4 & 1 & 2 & 3 \\
\hline \multicolumn{6}{|c|}{ KV 2’Nnn Değerlendirmeleri } \\
\hline En önemli faktör:F11 & \multicolumn{5}{|c|}{ En az önemli faktör: $\mathbf{F 1 2}$} \\
\hline \multicolumn{6}{|c|}{ En önemli faktörün diğer faktörlere göre ikili karşılaştırma vektörü } \\
\hline \multicolumn{2}{|l|}{ Değerlendirme } & F11 & F12 & F13 & F14 \\
\hline \multicolumn{2}{|l|}{ En önemli faktörün (F11) diğer faktörlere göre tercih oranı } & 1 & 5 & 2 & 3 \\
\hline \multicolumn{6}{|c|}{ Diğer faktörlerin en az önemli faktöre göre ikili karşılaştırma vektörü } \\
\hline \multicolumn{2}{|l|}{ Değerlendirme } & F11 & F12 & F13 & F14 \\
\hline \multicolumn{2}{|l|}{ Diğer faktörlerin en az önemli faktöre (F12) göre tercih oranı } & 5 & 1 & 4 & 3 \\
\hline \multicolumn{6}{|c|}{ KV 3'ün Değerlendirmeleri } \\
\hline En önemli faktör:F11 & \multicolumn{5}{|c|}{ En az önemli faktör:F12 } \\
\hline \multicolumn{6}{|c|}{ En önemli faktörün diğer faktörlere göre ikili karşılaştırma vektörü } \\
\hline \multicolumn{2}{|l|}{ Değerlendirme } & F11 & F12 & F13 & F14 \\
\hline \multicolumn{2}{|l|}{ En önemli faktörün (F11) diğer faktörlere göre tercih oranı } & 1 & 6 & 4 & 3 \\
\hline \multicolumn{6}{|c|}{ Diğer faktörlerin en az önemli faktöre göre ikili karşılaştırma vektörü } \\
\hline \multicolumn{2}{|l|}{ Değerlendirme } & F11 & F12 & F13 & F14 \\
\hline \multicolumn{2}{|l|}{ Diğer faktörlerin en az önemli faktöre (F12) göre tercih oranı } & 6 & 1 & 3 & 4 \\
\hline \multicolumn{6}{|c|}{ KV 4'ün Değerlendirmeleri } \\
\hline En önemli faktör: $\mathbf{F 1 4}$ & \multicolumn{5}{|c|}{ En az önemli faktör:F12 } \\
\hline En önemli faktörün diğer faktörlere göre ikili karşılaştırma & & & & & \\
\hline Değerlendirme & & F11 & F12 & F13 & F14 \\
\hline En önemli faktörün (F14) diğer faktörlere göre tercih oranı & & 2 & 6 & 4 & 1 \\
\hline Diğer faktörlerin en az önemli faktöre göre ikili karşılaştırn & & & & & \\
\hline Değerlendirme & & F11 & F12 & F13 & F14 \\
\hline Diğer faktörlerin en az önemli faktöre (F12) göre tercih oranı & & 4 & 1 & 6 & 3 \\
\hline KV 5'in & endirmeleri & & & & \\
\hline En önemli faktör:F11 & En az önem & $r: \mathbf{F 1 2}$ & & & \\
\hline En önemli faktörün diğer faktörlere göre ikili karşılaştırma & & & & & \\
\hline Değerlendirme & & F11 & F12 & F13 & F14 \\
\hline En önemli faktörün (F11) diğer faktörlere göre tercih oranı & & 1 & 6 & 4 & 2 \\
\hline Diğer faktörlerin en az önemli faktöre göre ikili karşılaştırr & & & & & \\
\hline Değerlendirme & & F11 & F12 & F13 & F14 \\
\hline Diğer faktörlerin en az önemli faktöre (F12) göre tercih oranı & & 5 & 1 & 3 & 4 \\
\hline
\end{tabular}


Mobilite ana faktörüne ait alt faktörlerin değerlendirmeleri ise Tablo 5'de verilmiştir.

Tablo 5. Mobilite ana faktörüne ait alt faktörlerin değerlendirmeleri

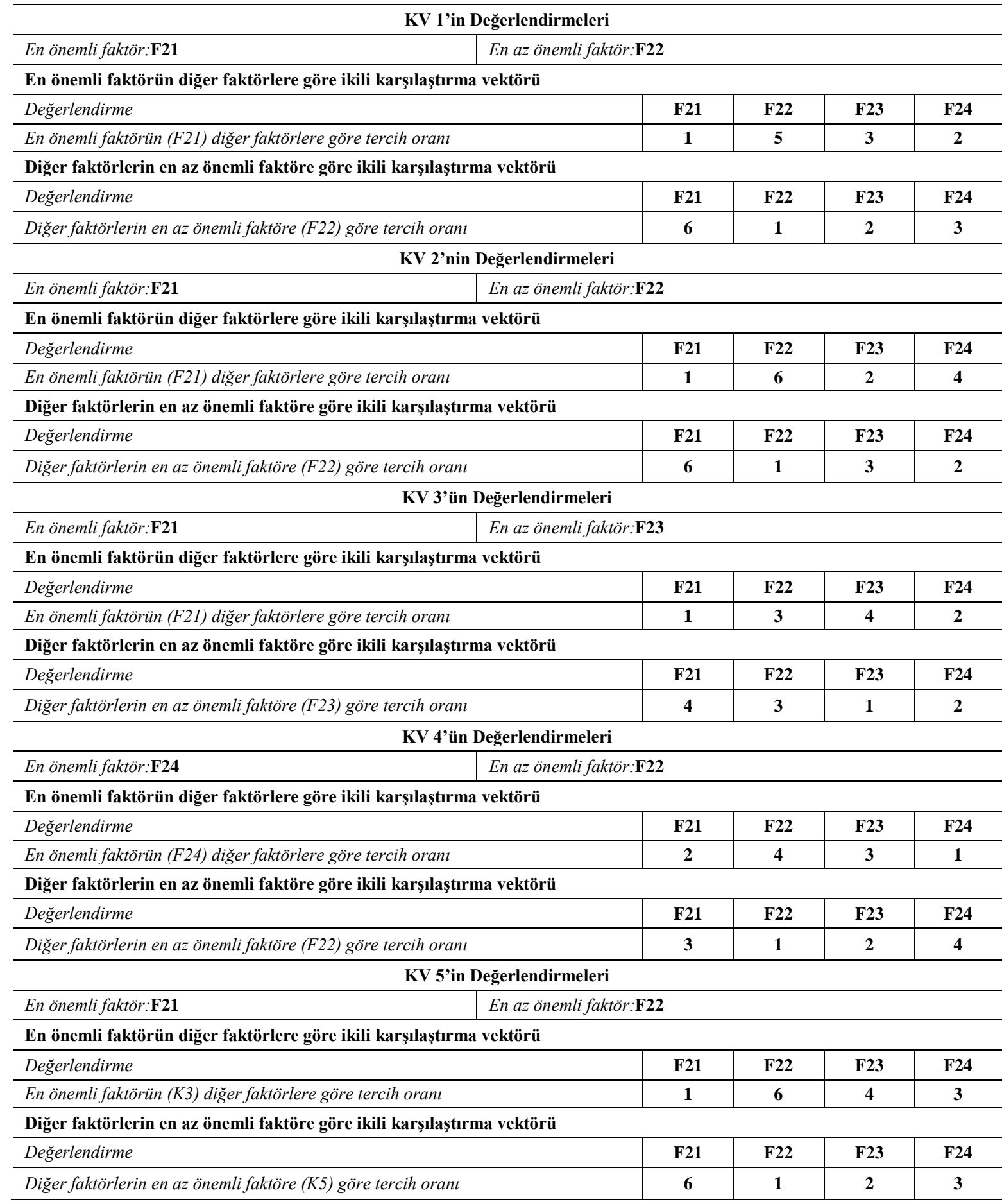


Moda ana faktörüne ait alt faktörlerin değerlendirmeleri ise Tablo 6'da verilmiştir.

Tablo 6. Moda ana faktörüne ait alt faktörlerin değerlendirmeleri

\begin{tabular}{|c|c|c|c|c|c|}
\hline \multicolumn{6}{|c|}{ KV 1'in Değerlendirmeleri } \\
\hline En önemli faktör:F32 & \multicolumn{5}{|l|}{ En az önemli faktör:F34 } \\
\hline \multicolumn{6}{|c|}{ En önemli faktörün diğer faktörlere göre ikili karşılaştırma vektörü } \\
\hline \multicolumn{2}{|l|}{ Değerlendirme } & F32 & F33 & F34 & F35 \\
\hline \multicolumn{2}{|l|}{ En önemli faktörün (F32) diğer faktörlere göre tercih oranı } & 1 & 4 & 5 & 3 \\
\hline \multicolumn{6}{|c|}{ Diğer faktörlerin en az önemli faktöre göre ikili karşılaştırma vektörü } \\
\hline \multicolumn{2}{|l|}{ Değerlendirme } & F32 & F33 & F34 & F35 \\
\hline \multicolumn{2}{|l|}{ Diğer faktörlerin en az önemli faktöre (F34) göre tercih oranı } & 6 & 2 & 1 & 3 \\
\hline \multicolumn{6}{|c|}{ KV 2'nin Değerlendirmeleri } \\
\hline En önemli faktör: F32 & \multicolumn{5}{|l|}{ En az önemli faktör: F33 } \\
\hline \multicolumn{6}{|c|}{ En önemli faktörün diğer faktörlere göre ikili karşılaştırma vektörü } \\
\hline \multicolumn{2}{|l|}{ Değerlendirme } & F32 & F33 & F34 & F35 \\
\hline \multicolumn{2}{|l|}{ En önemli faktörün (F32) diğer faktörlere göre tercih oranı } & 1 & 6 & 5 & 4 \\
\hline \multicolumn{6}{|c|}{ Diğer faktörlerin en az önemli faktöre göre ikili karşılaştırma vektörü } \\
\hline \multicolumn{2}{|l|}{ Değerlendirme } & F32 & F33 & F34 & F35 \\
\hline \multicolumn{2}{|l|}{ Diğer faktörlerin en az önemli faktöre (F33) göre tercih oranı } & 6 & 1 & 2 & 3 \\
\hline \multicolumn{6}{|c|}{ KV 3’ün Değerlendirmeleri } \\
\hline En önemli faktör:F31 & \multicolumn{5}{|l|}{ En az önemli faktör: $\mathbf{F 3 5}$} \\
\hline \multicolumn{6}{|c|}{ En önemli faktörün diğer faktörlere göre ikili karşılaştırma vektörü } \\
\hline \multicolumn{2}{|l|}{ Değerlendirme } & F32 & F33 & F34 & F35 \\
\hline \multicolumn{2}{|l|}{ En önemli faktörün (F31) diğer faktörlere göre tercih oranı } & 2 & 4 & 5 & 6 \\
\hline \multicolumn{6}{|c|}{ Diğer faktörlerin en az önemli faktöre göre ikili karşılaştırma vektörü } \\
\hline \multicolumn{2}{|l|}{ Değerlendirme } & F32 & F33 & F34 & F35 \\
\hline \multicolumn{2}{|l|}{ Diğer faktörlerin en az önemli faktöre (F35) göre tercih oranı } & 5 & 3 & 2 & 1 \\
\hline \multicolumn{6}{|c|}{ KV 4'ün Değerlendirmeleri } \\
\hline En önemli faktör: $\mathbf{F 3 2}$ & \multicolumn{5}{|l|}{ En az önemli faktör:F35 } \\
\hline En önemli faktörün diğer faktörlere göre ikili karşılaştırma & & & & & \\
\hline Değerlendirme & F31 & F32 & F33 & F34 & F35 \\
\hline En önemli faktörün (F32) diğer faktörlere göre tercih oranı & 2 & 1 & 4 & 5 & 6 \\
\hline Diğer faktörlerin en az önemli faktöre göre ikili karşılaştırı & örü & & & & \\
\hline Değerlendirme & F31 & F32 & F33 & F34 & F35 \\
\hline Diğer faktörlerin en az önemli faktöre (F35) göre tercih oranı & 6 & 7 & 3 & 2 & 1 \\
\hline KV 5'in & endirmeleri & & & & \\
\hline En önemli faktör: $\mathbf{F 3 2}$ & En az önemli faktör: $\mathbf{F 3 5}$ & & & & \\
\hline En önemli faktörün diğer faktörlere göre ikili karşılaştırma & & & & & \\
\hline Değerlendirme & F31 & F32 & F33 & F34 & F35 \\
\hline En önemli faktörün (F32) diğer faktörlere göre tercih oranı & 4 & 1 & 3 & 5 & 8 \\
\hline Diğer faktörlerin en az önemli faktöre göre ikili karşılaştırı & örü & & & & \\
\hline Değerlendirme & F31 & F32 & F33 & F34 & F35 \\
\hline Diğer faktörlerin en az önemli faktöre (F35) göre tercih oranı & 3 & 8 & 5 & 2 & 1 \\
\hline
\end{tabular}


Her bir karar vericiye ait ana faktörlerin ve alt faktörlerin ağırlıkları, tutarlılık oranları ve ortalama ağırlıklar ise Tablo 6, Tablo 8, Tablo 9 ve Tablo 10'da verilmiştir.

Tablo 7. Ana faktörlere ait ağırlıklar, tutarlılık oranları ve ortalama ağırlıklar

\begin{tabular}{c|c|c|c|c|c}
\hline Karar Vericiler & $\mathbf{W}_{\mathbf{F 1}}$ & $\mathbf{W}_{\mathbf{F 2}}$ & $\mathbf{W}_{\mathbf{F 3}}$ & $\boldsymbol{\xi}$ & Tutarlılık Oranı (TO) \\
\hline KV 1 & 0,647 & 0,235 & 0,117 & 0,058 & 0,058 \\
\hline KV 2 & 0,562 & 0,312 & 0,125 & 0,062 & 0,057 \\
\hline KV 3 & 0,628 & 0,228 & 0,142 & 0,041 & 0,057 \\
\hline KV 4 & 0,541 & 0,166 & 0,291 & 0,062 & 0,041 \\
\hline KV 5 & 0,687 & 0,187 & 0,125 & 0,062 & \\
\hline Son Ağırlıklar & 0,613 & 0,225 & 0,160 & & \\
\hline
\end{tabular}

Tablo 8. Akıllılık alt faktörlerine ait ağırlıklar, tutarlılık oranları ve ortalama ağırlıklar

\begin{tabular}{c|c|c|c|c|c|c}
\hline Karar Vericiler & $\mathbf{W}_{\mathbf{F 1 1}}$ & $\mathbf{W}_{\mathbf{F 1 2}}$ & $\mathbf{W}_{\mathbf{F 1 3}}$ & $\mathbf{W}_{\mathbf{F 1 4}}$ & $\boldsymbol{\xi}$ & Tutarlılık Oranı (TO) \\
\hline KV 1 & 0,465 & 0,103 & 0,172 & 0,258 & 0,051 & 0,031 \\
\hline KV 2 & 0,471 & 0,081 & 0,268 & 0,178 & 0,065 & 0,039 \\
\hline KV 3 & 0,549 & 0,076 & 0,160 & 0,213 & 0,091 & 0,055 \\
\hline KV 4 & 0,285 & 0,071 & 0,142 & 0,500 & 0,071 & 0,043 \\
\hline KV 5 & 0,486 & 0,078 & 0,144 & 0,289 & 0,092 & \\
\hline Son Ağırlıklar & 0,451 & 0,081 & 0,177 & 0,287 & & \\
\hline
\end{tabular}

Tablo 9. Mobilite alt faktörlerine ait ağırlıklar, tutarlılık oranları ve ortalama ağırlıklar

\begin{tabular}{|c|c|c|c|c|c|c|}
\hline Karar Vericiler & $W_{F 21}$ & $\mathbf{W}_{\mathrm{F} 22}$ & $W_{\text {F23 }}$ & $\mathbf{W}_{\mathrm{F} 24}$ & $\xi$ & Tutarlılık Oranı (TO) \\
\hline KV 1 & 0,478 & 0,086 & 0,173 & 0,260 & 0,043 & 0,026 \\
\hline KV 2 & 0,513 & 0,081 & 0,270 & 0,135 & 0,027 & 0,016 \\
\hline KV 3 & 0,454 & 0,181 & 0,090 & 0,272 & 0,090 & 0,055 \\
\hline KV 4 & 0,258 & 0,103 & 0,172 & 0,465 & 0,051 & 0,031 \\
\hline KV 5 & 0,559 & 0,084 & 0,152 & 0,203 & 0,050 & 0,030 \\
\hline Son Ă̆grlıklar & 0,452 & 0,107 & 0,171 & 0,267 & & \\
\hline
\end{tabular}

Tablo 10. Moda alt faktörlerine ait ağırlıklar, tutarlılık oranları ve ortalama ağırlıklar

\begin{tabular}{c|c|c|c|c|c|c|c}
\hline Karar Vericiler & $\mathbf{W}_{\mathbf{F 3 1}}$ & $\mathbf{W}_{\mathbf{F 3 2}}$ & $\mathbf{W}_{\mathbf{F 3 3}}$ & $\mathbf{W}_{\mathbf{F 3 4}}$ & $\mathbf{W}_{\mathbf{F 3 5}}$ & $\boldsymbol{\xi}$ & Tutarlılık Oranı (TO) \\
\hline KV 1 & 0,236 & 0,415 & 0,118 & 0,071 & 0,157 & 0,057 & 0,025 \\
\hline KV 2 & 0,256 & 0,448 & 0,064 & 0,102 & 0,128 & 0,064 & 0,028 \\
\hline KV 3 & 0,448 & 0,256 & 0,128 & 0,102 & 0,064 & 0,064 & 0,028 \\
\hline KV 4 & 0,263 & 0,439 & 0,131 & 0,105 & 0,058 & 0,087 & 0,038 \\
\hline KV 5 & 0,143 & 0,498 & 0,190 & 0,114 & 0,053 & 0,074 & \\
\hline Son Ağırlıklar & 0,269 & 0,411 & 0,126 & 0,098 & 0,092 & & \\
\hline
\end{tabular}

Tüm ana faktörlerin ağırlıkları ve tüm alt faktörlerin global ve yerel ağırlıkları Tablo 11'de verilmiştir.

Tablo 11. Tüm ana faktörlerin ağırlıkları ve tüm alt faktörlerin global ve yerel ağırlıkları

\begin{tabular}{|c|c|c|c|c|c|c|c|}
\hline $\begin{array}{c}\text { Ana } \\
\text { Faktörler }\end{array}$ & $\begin{array}{c}\text { Ana } \\
\text { Faktörlerin } \\
\text { Yerel } \\
\text { Ăğırlıkları } \\
\end{array}$ & $\begin{array}{c}\text { Ana } \\
\text { Faktörlerin } \\
\text { Siralaması }\end{array}$ & Alt Faktörler & $\begin{array}{c}\text { Alt } \\
\text { Faktörlerin } \\
\text { Yerel } \\
\text { Ăğırlıkları } \\
\end{array}$ & $\begin{array}{c}\text { Alt } \\
\text { Faktörlerin } \\
\text { Yerel } \\
\text { Suralaması } \\
\end{array}$ & $\begin{array}{c}\text { Alt Faktörlerin } \\
\text { Global } \\
\text { Ağırlıkları }\end{array}$ & $\begin{array}{c}\text { Alt Faktörlerin } \\
\text { Global } \\
\text { Siralaması }\end{array}$ \\
\hline \multirow{4}{*}{$\begin{array}{c}\text { F1: } \\
\text { Ak1llilık }\end{array}$} & \multirow{4}{*}{0,613} & \multirow{4}{*}{1} & F11: Bilgi Sağlama & 0,451 & 1 & 0,286 & 1 \\
\hline & & & F12: Sezgisel İletişim & 0,081 & 4 & 0,049 & 7 \\
\hline & & & F13: İletişim Ağ & 0,177 & 3 & 0,108 & 3 \\
\hline & & & F14: Otomasyon & 0,287 & 2 & 0,175 & 2 \\
\hline \multirow{4}{*}{$\begin{array}{c}\text { F2: } \\
\text { Mobilite }\end{array}$} & \multirow{4}{*}{0,225} & \multirow{4}{*}{2} & F21: Yaygın Bilişim & 0,452 & 1 & 0,101 & 4 \\
\hline & & & F22: Kolaylık & 0,107 & 4 & 0,024 & 10 \\
\hline & & & F23: Yerini Belirleme & 0,171 & 3 & 0,038 & 9 \\
\hline & & & F24: Kişiselleştirme & 0,267 & 2 & 0,060 & 6 \\
\hline \multirow{5}{*}{ F3: Moda } & \multirow{5}{*}{0,160} & \multirow{5}{*}{3} & F31: Sembol & 0,269 & 2 & 0,043 & 8 \\
\hline & & & F32: Kültür & 0,411 & 1 & 0,065 & 5 \\
\hline & & & F33: Yenilik & 0,126 & 3 & 0,020 & 11 \\
\hline & & & F34: Estetik & 0,098 & 4 & 0,015 & 12 \\
\hline & & & F35: Teknolojik & 0,092 & 5 & 0,014 & 13 \\
\hline
\end{tabular}




\begin{tabular}{|c|c|c|}
\hline & $\begin{array}{l}\text { BŞEÜ Fen Bilimleri Dergisi } \\
8(1), 136-150,2021\end{array}$ & $\begin{array}{r}\text { BSEU Journal of Science } \\
\text { https://doi.org/10.35193/bseufbd.847791 }\end{array}$ \\
\hline & & 2458-7575 (https://dergipark.org.tr/tr/pub/bseufbd) \\
\hline
\end{tabular}

Tablo 10'dan da anlaşılacağı gibi ana faktörler arasından akıllılık faktörü 0,613 yerel ağırlık değeriyle en önemli faktör olarak belirlenmiştir. Ana faktörler arasında bulunan moda faktörü ise 0,160 yerel ağırlık değeri ile en az öneme sahip faktör olarak belirlenmiştir. Alt faktörlerin global ağırlık değerleri incelendiğinde ise bilgi sağlama alt faktörü 0,276 global ağırlık değeri ile en önemli faktör, teknoloji alt faktörü ise 0,014 global ağırlık değeri ile en az önemli faktör olarak belirlenmiştir.

\section{DUYARLILIK ANALIZI}

Giyilebilir teknolojik ürün tasarımında etkili olan faktörlerin önem düzeylerini belirlemek amacıyla önerilen BWM yönteminin etkinliğini ve verimliliğini belirlemek için bir duyarlılık analizi yapılmıştır. Bu nedenle, BWM gibi sübjektif ağırlık belirleme yöntemleri sınıfında yer alan AHP ve FUCOM sübjektif ağırlıklandırma yöntemleriyle değerlendirmeler yapılarak faktör ağırlıkları ve kriter sıralamaları tespit edilmiştir. BWM metodunun yanında diğer iki metodun da seçilmesinin sebebi sübjektif olmalarının yanında tutarlılık oranını hesaplamalarıdır. Tablo 12'de elde edilen sonuçlara yer verilmiştir.

Tablo 12. Duyarlılık sonuçları

\begin{tabular}{cccc}
\hline Faktörler & BWM Sira & AHP Sira & FUCOM Sira \\
\hline F11 & 1 & 1 & 1 \\
F12 & 7 & 7 & 7 \\
F13 & 3 & 3 & 3 \\
F14 & 2 & 2 & 2 \\
F21 & 4 & 5 & 5 \\
F22 & 10 & 9 & 10 \\
F23 & 9 & 10 & 9 \\
F24 & 6 & 6 & 6 \\
F31 & 8 & 8 & 8 \\
F32 & 5 & 4 & 4 \\
F33 & 11 & 11 & 12 \\
F34 & 12 & 12 & 11 \\
F35 & 13 & 13 & 13 \\
\hline
\end{tabular}

Sonuçlar arasında oldukça güçlü bir benzerlik vardır. Sonuç olarak BWM yönteminin diğer yöntemlerle oldukça tutarlı sonuçlar verdiği söylenebilir. BWM, AHP ve FUCOM yöntemleri arasındaki korelasyon ve anlamlılık düzeyleri Tablo 13 'te verilmiştir.

Tablo 13. BWM, AHP ve FUCOM arasındaki korelasyon ve anlamlılık düzeyleri

\begin{tabular}{cccc}
\hline Spearman's rho & BWM & AHP & FUCOM \\
\hline \multirow{2}{*}{ BWM } & 1,000 &, $989^{* *}$ &, $989^{* *}$ \\
& $(0,000)$ & $(0,000)$ & $(0,000)$ \\
\multirow{2}{*}{ AHP } &, $989 * *$ & 1,000 &, $989 * *$ \\
& $(0,000)$ & $(0,000)$ & $(0,000)$ \\
\multirow{2}{*}{ FUCOM } &, $989^{* *}$ &, $989 * *$ & 1,000 \\
& $(0,000)$ & $(0,000)$ & $(0,000)$ \\
\hline
\end{tabular}

Tablo 13'ten de anlaşılacağı üzere BWM, AHP ve FUCOM yöntemleri ile elde edilen sıralamalar arasındaki korelasyonlar, her üç yöntemde de oldukça benzer sonuç verdiği bu şekilde belirtilerek, karar vericiler tarafından kullanılabileceğini ortaya çıkarılmıştır.

\section{SONUÇ}

Teknolojinin hızla gelişmesi sonucunda ortaya çıkan giyilebilir teknolojik ürünler günlük yaşantımızı kolaylaştırmaktadır. Bu ürünlerin tasarımı, hem üreticiler hem de tüketiciler için önem arz etmektedir. Tüketiciler açısından, satın alınması planlanan giyilebilir teknolojik ürünün estetik, kullanışı ve amacına uygun şekilde tasarlanmış olması beklenmekte ve bu özelliklere sahip olan ürünler arasından bir seçim yapılmaktadır. Üretici açısından ise yükselen küresel rekabete paralel olarak önemi artan giyilebilir teknoloji sektöründe rekabet üstünlüğünün ve sürekliliğinin sağlanması ve ürünlerin tasarımına yönelik çalışmalara öncelik verilmesi büyük 
önem arz etmektedir. Üretici firmalar tasarımlarını gerçekleştirirken tüketicilerin istek ve ihtiyaçlarını göz önünde bulundurmak durumundadırlar. Bu bağlamda, giyilebilir teknolojik ürünlerin tasarımında etkili olan birçok faktörün varlığından söz edilebilir. Bu faktörlerin önem derecelerinin belirlenmesi, üreticiye tasarım aşamasında hangi faktörlere daha fazla önem vermesi gerektiğine karar vermesinde ve buna bağlı olarak uygulanacak üretim stratejilerinin belirlenmesinde yardımcı olmaktadır. Çok kriterli karar verme yöntemleri, bu faktörlerin önem derecelerinin belirlenmesine imkan tanımaktadır.

Literatür incelendiğinde, giyilebilir teknoloji ile ilgili pek çok çalışma yapıldığı görülmektedir. Ancak Türkiye'de özellikle tüketiciler tarafından istenip, dikkate alınan tasarım faktörlerinin birden çok ÇKKV yöntemi ile değerlendirilmesine rastlanmamıştır. Bu çalışma, giyilebilir teknolojik ürünlerin tasarımında etkili olan faktörlerin birden ÇKKV yöntemi ile önceliklendirilmesini dolayısıyla da literatürdeki boşluğu doldurmayı amaçlamaktadır. Değerlendirmeler sonucunda, tasarımda etkili olan en önemli ve en az önemli ana faktörler ve alt faktörler belirlenmektedir.

Bu bağlamda, öncelikle giyilebilir teknolojik ürünlerin tasarımında etkili olan 3 ana faktör akılllllk, mobilite ve moda faktörleri belirlenmiştir. Bu ana faktörler ise kendi içerisinde alt faktörlere ayrılmaktadır. Akılllık ana faktörü; bilgi sağlama, sezgisel iletişim, iletişim ağı ve otomasyon olmak üzere 4 alt faktörden oluşmaktadır. Mobilite ana faktörü; yaygın bilişim, kolaylık, yerini belirleme ve kişiselleştirme olmak üzere 4 alt faktörden meydana gelmektedir. Moda ana faktörü ise; sembol, kültür, yenilik, estetik ve teknoloji olmak üzere 5 alt faktörden oluşmaktadır. Ana ve alt faktörler, giyilebilir teknolojik ürünlerin tasarımında uzman 5 karar vericinin görüşleri alınarak Best-Worst metodu kullanılarak değerlendirilmiştir. Değerlendirme sonucunda, ana faktörler arasından akıllılık faktörü 0,613 yerel ağırlık değeriyle en önemli faktör olarak belirlenmiştir. Ana faktörler arasında bulunan moda faktörü ise 0,160 yerel ağılık değeri ile en az öneme sahip faktör olarak belirlenmiştir. Giyilebilir teknolojik ürünler, sektördeki kullanım amaçları bakımından dış görünümden ziyade işlevsel olması gereken ürünler olduğundan akıllı1ık faktörünün yüksek, moda faktörünün ise düşük ağırlıkta çıkması aslında beklenen bir durumdur. Alt faktörlerin global ağırlık değerleri incelendiğinde ise bilgi sağlama alt faktörü 0,276 global ağırlık değeri ile en önemli faktör, teknoloji alt faktörü ise 0,014 global ağırlık değeri ile en az önemli faktör olarak belirlenmiştir. Günümüzde toplumdaki bireylerin giyilebilir teknolojik ürünlerden beklentilerinin daha çok bilgi edinmek olduğu düşünüldüğünde, bilgi sağlama alt faktörünün en önemli faktör olarak belirlenmesi rasyonel görünmektedir. Öte yandan teknoloji alt faktörünün en az önemli faktör olarak çıkması ise müşsterilerin ürünlerden temel beklentisinin işlevsellik olduğunu göstermektedir.Bu durum yeterince işlevsel olarak algılanan ürün kategorilerinde müşterilerin teknolojiye daha az önem verdikleri yönünde değerlendirilebilir.Ayrıca, çalışmada her bir ana faktöre ait alt faktörlerin kendi içerisinde önceliklendirilmesi de elde edilmiştir. Akillllık ana faktöründeki alt faktörler incelendiğinde, en fazla öneme sahip olan faktör bilgi sağlama iken en az öneme sahip olan faktör sezgisel iletişim olmuştur. Mobilite ana faktörünün alt faktörleri incelendiğinde, en fazla öneme sahip olan faktör yaygın bilişim iken en az öneme sahip faktör kolaylık faktörü olarak belirlenmiştir. Moda ana faktörünün alt faktörleri incelendiğinde ise kültür faktörü en fazla öneme sahip iken teknoloji en az öneme sahip faktör olarak belirlenmiştir.

$\mathrm{Bu}$ çalı̧̧ma bazı sınırlııkları kapsamaktadır. Bu sınırlılıkların başında, giyilebilir teknolojik ürünlerin tasarımında çalışan beş uzmanın belli kriterler dahilinde görüşlerinin alınması gelmektedir. Ayrıca çalışma, BWM, AHP ve FUCOM yöntemlerinin mutlak sayıların kullanımıyla gerçekleştirilmiştir. İleriki çalışmalarda uzman sayısı ve kriter sayısı artırılarak, farklı sayı tiplerinde, farklı yöntemler kullanılarak geliştirilebilir. Son olarak, bu çalışmanın giyilebilir teknolojik ürün yaklaşımını uygulamaya istekli olan şirketlere ve karar vericilere yol göstereceği beklenmektedir.

\section{ETIKK KURUL KARARI}

"Giyilebilir Teknolojik Ürünlerin Tasarımında Etkili Olan Faktörlerin BestWorst Metodu (BWM) İle Değerlendirilmesi" isimli çalışma için, Bilecik Şeyh Edebali Üniversitesi Etik Kurulu'nun 26.02.2021 tarihli ve 3 sayılı toplantısının 1 nolu kararı ile etiğe aykırılık bulunmadığına karar verilmiştir. 


\section{KAYNAKLAR}

[1] Özgüner Kılıç, H. (2017). Giyilebilir Teknoloji Ürünleri Pazarı ve Kullanım Alanları. Aksaray Üniversitesi İktisadi ve İdari Bilimler Fakültesi Dergisi, 9 (4), 99-112.

[2] Gepperth, J. (2012). Smart Things: Wearables \& Clothing. Smart Things, 3, 41-48.

[3] Thorp, E. O. (1961). A Favorable Strategy for Twenty-One. Proceedings of the National Academy of Sciences, 47 (1), 110-112.

[4] Sağbaş, E. A., Ballı, S. \& Yıldız, T. (2016). Giyilebilir Akıllı Cihazlar: Dünü, Bugünü ve Geleceği. 18. Akademik Bilişim Konferansı içinde (ss. 749-756). Aydın, Türkiye.

[5] Erdem İşmal, Ö. \& Yüksel, E. (2016). Tekstil ve Moda Tasarımına Teknolojik Bir Yaklaşım: Akıllı ve Renk Değiştiren Tekstiller. Yedi: Sanat, Tasarım ve Bilim Dergisi, 16, 87-98.

[6] Barfield, W. \& Caudell, T. (2001). Basic Concepts in Wearable Computers and Augmented Reality. W. Barfield \& T. Caudell (Ed.), Fundamentals of Wearable Computers and Augumented Reality içinde . New Jersey: Lawrence Erlbaum Associates.

[7] Page, T. (2015). Privacy Issues Surrounding Wearable Technology. i-Manager's Journal on Information Technology, 4 (4), 1-16.

[8] Karamehmet, B. (2019). Dijital Pazarlamada Nesnelerin İnterneti: Giyilebilir Teknolojiler. Journal of Turkish Studies, 14 (2), 521-537. doi:10.7827/TurkishStudies.14997

[9] Albayrak, Ö. \& Erkayman, B. (2018). Bulanık Dematel ve Edas Yöntemleri Kullanılarak Sporcular İçin Akıllı Bileklik Seçimi. Ergonomi, 1 (2), 92-102. doi:10.33439/ergonomi.478303

[10] Sönmez Çakır, F., Aytekin, A. \& Tüminçin, F. (2018). Nesnelerin İnterneti ve Giyilebilir Teknolojiler. Sosyal Araştırmalar ve Davranış Bilimleri Dergisi, 4 (5), 84-95.

[11] Kuzu, S. (2015). VIKOR. B. F. Yıldırım ve E. Önder (Ed.), Çok Kriterli Karar Verme Yöntemleri içinde (2. Baski.). Bursa: Dora Yayın.

[12] Ayçin, E. (2019). Çok Kriterli Karar Verme: Bilgisayar Uygulamalı Çözümler. Ankara: Nobel.

[13] Rezaei, J. (2015). Best-worst multi-criteria decision-making method. Omega, 53, 49-57.

[14] Kolat, D., Ajlan Kökçü, H., Kiranli, M., Özbiltekin, M. \& Öztürkoğlu, Y. (2020). Measuring Service Quality in the Logistic Sector by Using Servqual and Best Worst Method. N. M. Durakbasa ve M. G. Gençyilmaz (Ed.), Proceedings of the International Symposium for Production Research 2019 içinde (ss. 720-731). Cham: Springer. doi:10.1007/978-3-030-31343-2_61

[15] Akyüz, G., Tosun, Ö. \& Aka, S. (2020). Performance Evaluation Of Non-Life Insurance Companies with Best-Worst Method And Topsis. International Journal of Management Economics and Business, 16 (1), 108 125. doi:10.17130/ijmeb.700907

[16] Çetinkaya, V. \& Deveci, D. A. (2020). Optimal Sürdürülebilir Rota Tespiti için Gerekli Göstergelerin Birçok Kriterli Karar Verme Yöntemi ile Önem Düzeyi Tespiti. Dokuz Eylül Üniversitesi Denizcilik Fakültesi Dergisi, 12 (1), 25-46. doi:10.18613/deudfd.775117

[17] Çakır, E. \& Can, M. (2019). Best-Worst Yöntemine Dayalı ARAS Yöntemi ile Dış Kaynak Kullanım Tercihinin Belirlenmesi: Turizm Sektöründe Bir Uygulama. Atatürk Üniversitesi Sosyal Bilimler Enstitüsü Dergisi, 23 (3), 1273-1300.

[18] Aşan, H. \& Ayçin, E. (2020). Kurumsal Kaynak Planlama Sistemlerinin Seçimindeki Kriterlerin Best-Worst Metodu ile Değerlendirilmesi. Bitlis Eren Üniversitesi İktisadi Ve İdari Bilimler Fakültesi Akademik İzdüşüm Dergisi, 5 (2), 114-124.

[19] Moslem, S., Farooq, D., Ghorbanzadeh, O., \& Blaschke, T. (2020). Application of the AHP-BWM model for evaluating driver behavior factors related to road safety: A case study for Budapest. Symmetry, 12 (2), 243.

[20] Guo, S. \& Zhao, H. (2017). Fuzzy Best-Worst Multi-Criteria Decision-Making Method and Its Applications. Knowledge-Based Systems, 121, 23-31. doi:10.1016/j.knosys.2017.01.010

[21] Askarifar, K., Motaffef, Z. \& Aazaami, S. (2018). An investment development framework in Iran's seashores using TOPSIS and best-worst multi-criteria decision making methods. Decision Science Letters, 7 (1), 5564. doi:10.5267/j.dsl.2017.4.004

[22] Rezaei, J., Nispeling, T., Sarkis, J. \& Tavasszy, L. (2016). A Supplier Selection Life Cycle Approach Integrating Traditional And Environmental Criteria Using The Best Worst Method. Journal of Cleaner Production, 135, 577-588. doi:10.1016/j.jclepro.2016.06.125 
[23] Kujlu, R., Moslemzadeh, M., Rahimi, S., Aghayani, E., Ghanbari, F. \& Mahdavianpour, M. (2020). Selecting the best stabilization/solidification method for the treatment of oil-contaminated soils using simple and applied best-worst multi-criteria decision-making method. Environmental Pollution, 263, 1-9. doi:10.1016/j.envpol.2020.114447

[24] Ren, J., Liang, H. \& Chan, F. T. S. (2017). Urban sewage Sludge, Sustainability, and Transition for EcoCity: Multi-Criteria Sustainability Assessment of Technologies Based on Best-Worst Method. Technological Forecasting and Social Change, 116, 29-39. doi:10.1016/j.techfore.2016.10.070

[25] Badri Ahmadi, H., Kusi-Sarpong, S. \& Rezaei, J. (2017). Assessing the social sustainability of supply chains using Best Worst Method. Resources, Conservation and Recycling, 126, 99-106. doi:10.1016/j.resconrec.2017.07.020

[26] Gupta, H. \& Barua, M. K. (2017). Supplier Selection Among SMEs on The Basis Of Their Green Innovation Ability Using BWM and fuzzy TOPSIS. Journal of Cleaner Production, 152, 242-258. doi:10.1016/j.jclepro.2017.03.125

[27] Chitsaz, N. \& Azarnivand, A. (2017). Water Scarcity Management in Arid Regions Based on an Extended Multiple Criteria Technique. Water Resources Management, 31 (1), 233-250. doi:10.1007/s11269-0161521-5

[28] Gupta, H. \& Barua, M. K. (2016). Identifying Enablers of Technological İnnovation for Indian MSMEs Using Best-Worst Multi Criteria Decision Making Method. Technological Forecasting and Social Change, 107, 69-79. doi:10.1016/j.techfore.2016.03.028

[29] Salimi, N. (2017). Quality Assessment of Scientific Outputs Using The BWM. Scientometrics, 112 (1), 195213. doi:10.1007/s11192-017-2284-3

[30] Guo, S. \& Zhao, H. (2017).Fuzzy best-worst multi-criteria decision-making method and its applications. Knowledge-Based Systems, 121, 23-31.

[31] Mi, X., Tang, M., Liao, H., Shen, W. \& Lev, B. (2019). The state-of-the-art survey on integrations and applications of the best worst method in decision making: Why, what, what for and what's next?. Omega, 87, 205-225.

[32] Rezaei, J., van Roekel, W. S. \& Tavasszy L. (2018). Measuring the relative importance of the logistics performance index indicators using Best Worst Method.Transport Policy, 68, 158-169.

[33] Rezaei, J. (2020). A Concentration Ratio for Nonlinear Best Worst Method. International Journal of Information Technology \& Decision Making, 19, (3), 891-907.

[34] Salimi, N. \& Rezaei, J. (2016). Measuring efficiency of university-industry Ph.D. projects using best worst method. Scientometrics, 109, 1911-1938.

[35] Demir, G. \& Bircan, H. (2020). Kriter Ağırlıklandırma Yöntemlerinden Bwm Ve Fucom Yöntemlerinin Karşılaştırılması ve Bir Uygulama.Sivas Cumhuriyet Üniversitesi İktisadi ve İdari Bilimler Dergisi, 21, (2), 170-185.

[36] Rençber, Ö.F. (2018). Finansal Oranların Önem Düzeylerinin Hesaplanmasında Ahp Ve Bwm Yöntemlerinin Karş1laştırılması. ICOAEF'18 IV. International Conference on Applied Economics and Finance \& Extended with Social Sciences. November 28-29-30, / Kuşadas1 - Turkey.

[37] Özmen, M., (2020). Bwm-Edas Yöntemi ile Ülkelerin Seyahat Ve Turizm Rekabetedebilirliğinin Değerlendirilmesi. Geleceğin Dünyasında Bilimsel Ve Mesleki Çalışmalar (pp.40-61), Bursa: Ekin BasımYayın Dağıtım.

[38] Şenyiğit E. \& Ünal Z. (2019). BWM-MOPA Yöntemi ile En İyi RFID Sisteminin Belirlenmesi. Avrupa Bilim ve Teknoloji Dergisi, Özel Sayl, 9-14.

[39] Çetin, M. S. \& Erdem, D. (2019). İletken İplik Alımında Etkili Kriterler Arasındaki İlişkilerin DEMATEL Yöntemi İle Belirlenmesi. European Journal of Science and Technology, (17), 152-160. doi:10.31590/ejosat.593034

[40] Deringöz, A., Danışan, T. \& Eren, T. (2020). Covid-19 Takibinde Giyilebilir Sağlık Teknolojilerinin ÇKKV Yöntemleri ile Değerlendirilmesi. Journal of Polytechnic, 1-1. doi:10.2339/politeknik.768219

[41] Bulğurcu, B. (2019). Çok Nitelikli Fayda Teorisi ile CRITIC Yöntem Entegrasyonu: Akıllı Teknoloji Tercih Örneği. OPUS Uluslararası Toplum Araştırmaları Dergisi, 13 (19), 1930-1957. doi:10.26466/opus.584123

[42] Albayrak, Ö. \& Erkayman, B. (2018). Bulanık Dematel ve Edas Yöntemleri Kullanılarak Sporcular İçin Akıllı Bileklik Seçimi. Ergonomi, 1 (2), 92-102. doi:10.33439/ergonomi.478303

[43] Belge, S. \& Mutlu, H. M. (2020). Tüketicilerin Giyilebilir Teknolojileri Benimsenmesine Yönelik Davranışsal Niyet Ve Kullanımları Üzerine Bir Araştırma. Uygulamalı Sosyal Bilimler Dergisi, 4 (1), 14- 
35.

[44] Aydan, S. \& Aydan, M. (2016). Sağlık Hizmetlerinde Bireysel Ölçüm ve Giyilebilir Teknoloji: Olası Katkıları, Güncel Durum ve Öneriler. Hacettepe Sağllk İdaresi Dergisi, 19 (3), 325-342.

[45] Marangoz, M. ve Aydın, A. E. (2018). Tüketicilerin Giyilebilir Teknoloji Ürünlerini Benimsemesinde Etkili Olan Faktörler. Pazarlama Teorisi ve Uygulamaları Dergisi, 4 (1), 1-20.

[46] Ada, A. \& Aksoy, R. (2020). Giyilebilir Teknolojik Ürünlerde Tüketicilerin Algıladıkları Risklerin Farklılaşması: Akıllı Saat Kullanıcılarına Dönük Bir Araştırma. Herkes için Spor ve Rekreasyon Dergisi, 2 (1), 50-61.

[47] Erol, A. D. \& Çetiner, S. (2017). Giyilebilir Elektronik/Akıllı Tekstiller ve Uygulamaları. KSU Mühendislik Bilimleri Dergisi, 20 (1), 1-20.

[48] Kao, C. H., Yang, C. M., Hsieh, C. H., \& Hung, Y. S. (2013). Decision making in the design process of wearable IT products. In 5th International Congress of International Association of Societies of Design Research (IASDR), Tokyo (8), 26-35.

[49] Rezaei, J., Wang, J., \& Tavasszy, L. (2015). Linking supplier development to supplier segmentation using Best Worst Method. Expert Systems with Applications, 42 (23), 9152-9164.

[50] Rezaei, J. (2016). Best-worst multi-criteria decision-making method: Some properties and a linear model. Omega, 64, 126-130. 